\title{
FREQUÊNCIAS DO FORNECIMENTO DA DIETA SOBRE AS CARACTERÍSTICAS DA CARCAÇA BOVINA EM CONFINAMENTO
}

\author{
FREQUENCY OF SUPPLY OF DIET OVER THE CHARACTERISTICS OF BOVINE \\ CARCASS IN FEEDLOT
}

\author{
Pazdiora, R.D. ${ }^{1 *}$; Paula, P.C. ${ }^{4}$;Callegaro, A.M. ${ }^{4}$; Metz, P.A.M. ${ }^{2}$; Silveira, M.F. ${ }^{2}$; \\ Menezes, L.F.G. ${ }^{2}$; Arboitte, M.Z. ${ }^{3}$; Brondani, I.L. ; Alves Filho, D.C. ${ }^{4}$ e Moura, A.F. de ${ }^{4}$ \\ 'Departamento de Medicina Veterinária. Universidade Federal de Rondônia (UNIR). Rolim de Moura. \\ Rondônia. Brasil. *pazdiora@yahoo.com.br \\ ${ }^{2}$ Universidade Tecnológica Federal do Paraná (UTFPR). Dois Vizinhos. Paraná. Brasil. \\ ${ }^{3}$ Instituto Federal Catarinense. Campus Sombrio. Sombrio. Santa Catarina. Brasil. \\ ${ }^{4}$ Departamento de Zootecnia. Universidade Federal de Santa Maria (UFSM). Santa Maria-RS. Brasil.
}

\section{PalaVRas ChaVE ADICIONAIS}

Área de olho de lombo. Cortes comerciais. Cruzamento. Gordura subcutânea.

\section{RESUMO}

Objetivou-se avaliar a influência de diferentes freqüências do fornecimento do volumoso e concentrado sobre as características da carcaça nas categorias vaca e novilha, terminadas em confinamento. Foram utilizadas 16 novilhas e 16 vacas, com idade média de 20 e 66 meses e peso médio inicial de 338 e $432 \mathrm{~kg}$, respectivamente, provenientes de gerações avançadas do cruzamento rotativo contínuo entre as raças Charolês e Nelore. Os tratamentos representados pelas freqüências do fornecimento do volumoso (V) e do concentrado (C), foram: $2 \mathrm{~V} / \mathrm{C}$ ( $\mathrm{V}$ e $\mathrm{C}$ duas vezes ao dia); $1 \mathrm{~V} / \mathrm{C}$ (V e C uma vez ao dia); $1 \mathrm{~V} /$ $2 \mathrm{C}$ (V uma vez e o $\mathrm{C}$ duas vezes ao dia); $1 \mathrm{~V} / 3 \mathrm{C}$ ( $V$ uma vez e o $C$ três vezes ao dia). Cada fornecimento alimentar foi ofertado às categorias vaca e novilha. A dieta fornecida foi composta de $60 \%$ de silagem de milho e $40 \%$ de concentrado com base na matéria seca. $\mathrm{O}$ abate foi realizado em frigorífico comercial, seguindo as normas do estabelecimento. $O$ delineamento experimental utilizado foi inteiramente casualizado em arranjo fatorial $4 \times 2$ (fornecimento $x$ categoria). Os dados foram submetidos à análise de variância e as médias comparadas pelo teste $t$. Não houve interação significativa entre freqüência de fornecimento e categoria animal. A freqüência de fornecimento não promoveu alterações nas ca-

\section{AdDitionAL KEYWORDS}

Commercial cuts. Croosbreed. Subcutaneous fat thickness. Rib eye area.

racterísticas da carcaça avaliadas $(p>0,05)$. As vacas apresentaram maior peso de abate e de carcaça quente e fria em relação às novilhas $(525,5 ; 291,0 ; 281,7$ kg vs. 424,7; 236,1;227,5 kg, respectivamente). Entretanto, as carcaças das novilhas apresentaram maior porcentagem de traseiro do que as vacas.

\section{SUMMARY}

The influence of different frequencies of supply of roughage and supplement on carcass characteristics of feedlot cows and heifers was studied. Sixteen heifers and sixteen cows, with average age of 20 and 66 months and initial weight of 338 and $432 \mathrm{~kg}$, respectively, from advanced generations of Charolais and Nellore continuous rotational crossbreeding were used. The treatments, representing the frequencies of the supply of roughage $(\mathrm{V})$ and concentrate $(\mathrm{C})$, were: $2 \mathrm{~V} / \mathrm{C}$ (V and $\mathrm{C}$ twice a day); $1 \mathrm{~V} / \mathrm{C}$ (V and $\mathrm{C}$ once a day); $1 \mathrm{~V} / 2 \mathrm{C}$ (V once a day and $\mathrm{C}$ twice a day); $1 \mathrm{~V} / 3 \mathrm{C}$ ( $\mathrm{V}$ once a day and $\mathrm{C}$ three times a day). Each treatment was offered to cows and heifers. The supplied diet was composed by $60 \%$ of corn silage and $40 \%$ of concentrate, on dry matter basis. The slaughter was carried out in commercial refrigerated slaugher house, following 


\section{PAZDIORA ETAL.}

the rules of the establishment. The complete randomized experimental design was used, with a factorial arrangement of $4 \times 2$ (frequency of supply $x$ category). Data were submitted to a variance analysis and the means were compared by $t$ test. No significant interaction was observed between frequency of supply and animal category. The frequency of supply did not change the evaluated carcass characteristics $(p>0.05)$. The cows presented higher slaughter weight and hot and cold carcass weights when compared to heifers $(525.5,291.0,281.7 \mathrm{~kg}$ vs. 424.7, 236.1, $227.5 \mathrm{~kg}$, respectively). However, the carcasses of heifers showeda higher percentage of rear cows.

\section{INTRODUÇÃO}

No momento atual da pecuária, a escolha do melhor manejo alimentar é fundamental, pois se reflete no desempenho animal e no retorno econômico para o produtor. A intensificação do sistema produtivo requer maior desembolso de capital, e por consequência, diferentes manejos vêm sendo pesquisados para melhorar a produtividade e a rentabilidade do sistema. $\mathrm{O}$ aumento do fornecimento da dieta vem sendo testado com estes objetivos, principalmente por estimular o animal a ingerir mais alimento (Chase et al., 1976), o que pode promover aumento no consumo de matéria seca (CMS) e desempenho produtivo, refletindo em carcaças de melhor conformação e qualidade.

Tradicionalmente, os produtores fornecem dieta completa em uma ou duas vezes ao dia, de acordo com as condições das instalações, vida útil do alimento no cocho e ao dispêndio econômico envolvido na atividade. Os custos requeridos com o transporte e a distribuição diária da dieta, por exemplo, são bastante expressivos, e devem ser bem planejados de modo que maximizem os lucros do produtor. $\mathrm{O}$ fracionamento do concentrado em detrimento do volumoso pode ser alternativa viável por este apresentar alta concentração de nutrientes por unidade de massa e reduzir os picos de ingestão, mantendo as concentrações de metabólicos ruminais mais estáveis. Entre- tanto, ainda são poucos os trabalhos que trazem informações a respeito das características da carcaça de animais alimentados com diferentes frequências de fornecimento do alimento.

No sistema de ciclo completo, o abate de fêmeas é importante fonte de renda para os produtores. O abate de fêmeas vem crescendo na última década, sendo para renovar o plantel de matrizes e melhorar os índices reprodutivos do rebanho ou para repor perdas econômicas em fases de crise na pecuária. No entanto, os animais à medida que a idade avança são menos eficientes na transformação do alimento consumido em ganho de peso, tornando o sistema menos produtivos. Atrelado ao bom desempenho animal, está à produção de carcaças de melhor qualidade, uma vez que, o Brasil possui a posição de maior exportador mundial de carne bovina (ANUALPEC, 2010), portanto, a utilização de animais e o manejo alimentar adotado são importantes para que o país se mantenha nesta posição, além do vasto mercado interno que pode ser melhor explorado.

Sendo assim, objetivou-se avaliar as características da carcaça de vacas e novilhas terminadas em confinamento, submetidas a diferentes manejos alimentares.

\section{MATERIALE MÉTODOS}

O experimento foi conduzido no Laboratório de Bovinocultura de Corte do Departamento de Zootecnia da Universidade Federal de Santa Maria (UFSM), situado na região denominada Depressão Central do Rio Grande do Sul.

Foram utilizadas 16 novilhas com idade média de 20 meses e peso médio de $338 \mathrm{~kg}$ e 16 vacas com idade média de 66 meses e $432 \mathrm{~kg}$ de peso médio ao início do período de avaliação, sendo os animais mestiços da terceira (5/8Charolês 3/8Nelore e 5/8Nelore 3/8Charolês) e quarta (11/16Charolês 5/ 16 Nelore e $11 / 16$ Nelore 5/16Charolês) gerações do cruzamento rotativo contínuo 


\section{FREQUÊNCIAS DA ALIMENTAÇÃO E CARACTERÍSTICAS DA CARCAÇA BOVINA}

entre as raças Charolês e Nelore. Os animais foram confinados em baias de $20 \mathrm{~m}^{2}$ parcialmente cobertos, com piso de alvenaria, com bebedouro regulado por torneira-bóia e disponibilidade de $2 \mathrm{~m}$ linear de cocho por animal. Todas as baias receberam dois animais de mesma categoria.

Foram adotados quatro manejos alimentares conforme as frequências do fornecimento do volumoso (V) e concentrado (C), que foram os seguintes: $2 \mathrm{~V} / \mathrm{C}$ ( V e C duas vezes ao dia fornecidos em parte iguais, às 8 e às 18 horas $) ; 1 \mathrm{~V} / \mathrm{C}$ ( $\mathrm{V}$ e $\mathrm{C}$ uma vez ao dia, $8 \mathrm{~h}$ ); $1 \mathrm{~V} / 2 \mathrm{C}$ (V uma vez ao dia, $8 \mathrm{~h}$ e o $\mathrm{C}$ duas vezes ao dia, 8 e $18 \mathrm{~h}$ ); $1 \mathrm{~V} / 3 \mathrm{C}$ (V uma vez ao dia, 8 h e o $C$ três vezes ao dia, 8,13 e $18 \mathrm{~h}$ ). Cada manejo alimentar foi realizado nas categorias vaca e novilha.

O confinamento teve duração de 79 dias, sendo 16 dias de adaptação dos animais às instalações, manejo e alimentação, e 63 dias de avaliações. A dieta fornecida aos animais foi composta de $60 \%$ de silagem de milho e $40 \%$ de concentrado com base na matéria seca, misturados no cocho, com o objetivo inicial de atender à exigência de proteína bruta para o ganho médio diário (GMD) de $1,200 \mathrm{~kg}$ (NRC, 1996) estimando consumo de $2,5 \mathrm{~kg}$ de matéria seca $/ 100 \mathrm{~kg}$ de peso corporal (PC), sendo apresentada na tabela I a composição da dieta utilizada no período experimental. A quantidade de alimento oferecida por dia foi regulada procurandose manter as sobras em $10 \%$ da quantidade ofertada. Para tanto, foram coletadas as sobras diariamente às $7 \mathrm{~h} 30 \mathrm{~min}$ a fim de medir o consumo do dia anterior e ajustar o fornecimento do dia subsequiente.

Antes do embarque para o frigorífico, os animais foram submetidos ao jejum de sólidos e líquidos de 14 horas, sendo posteriormente pesados, obtendo-se, dessa maneira, o peso de abate. Os animais foram transportados em caminhão boiadeiro por $25 \mathrm{~km}$ até o frigorífico comercial, procedendo-se o abate logo após o desembarque dos mesmos, obedecendo ao fluxo de abate normal do estabelecimento. Ao fim da linha de abate, as duas meia-carcaças foram lavadas, identificadas e pesadas, sendo em seguida conduzidas à câmara fria por um período de $24 \mathrm{~h}$, à temperatura de $0^{\circ} \mathrm{C}$. Após refrigeração, foram pesadas e avaliadas quanto à conformação, baseada na expressão muscular, e a maturidade fisiológica, calculada pelo grau de ossificação das cartilagens variando de níveis de mais a menos, seguindo a metodologia descrita por Müller (1987).

Os rendimentos de carcaças quente e fria, ambos expressos em percentual, foram obtidos pela relação entre o peso de carcaça quente e fria e o peso registrado na fazenda. A perda ao resfriamento foi calculada pela relação entre os pesos de carcaças fria e quente, registrados após e antes do processo de refrigeração, respectivamente.

Na meia-carcaça direita foram tomadas, primeiramente, as medidas métricas, como comprimento de carcaça, que correspondeu à medida do bordo anterior do osso púbis ao

Tabela I. Composição da dieta utilizada. (Composition of used diet).

\begin{tabular}{lcc}
\hline & Novilha & Vaca \\
\hline Componentes, \% & & \\
Silagem de milho & 60,0 & 60,0 \\
Grão de milho & 10,0 & 6,0 \\
Farelo de trigo & 16,2 & 22,44 \\
Farelo de glúten de milho & 12,0 & 10,0 \\
Uréia & 0,48 & 0,32 \\
Calcário calcítico & 0,88 & 0,82 \\
Cloreto de sódio & 0,40 & 0,40 \\
Rumensin® & 0,016 & 0,012 \\
Sulfato de amônia & 0,03 & 0,02 \\
& & \\
Composição nutricional, \% MS & & \\
Matéria seca & 54,91 & 54,97 \\
Matéria orgânica & 90,09 & 90,07 \\
Proteína bruta & 12,89 & 12,10 \\
Extrato etéreo & 3,19 & 3,14 \\
Fibra em detergente neutro & 35,87 & 32,90 \\
Fibra em detergente ácido & 18,49 & 19,45 \\
Carboidratos não fibrosos & 38,14 & 41,93 \\
Nutrientes digestíveis totais & 71,53 & 71,66 \\
\hline
\end{tabular}


bordo anterior medial da primeira costela, comprimento de perna e braço, espessura de coxão, medida com auxílio de compasso posicionado entre a face lateral e a medial da porção superior do coxão, e perímetro de braço, que correspondeu à circunferência medial do membro, segundo Muller (1987).

A meia-carcaça direita foi separada nos cortes dianteiro, compreendendo pescoço, paleta, braço e cinco costelas anteriores; costilhar (ponta de agulha), a partir da sexta costela mais os músculos abdominais; e o serrote (traseiro especial), constituído pelo posterior da carcaça. Esses cortes foram pesados, para posterior cálculo da participação percentual em relação à meia-carcaça. A compacidade da carcaça foi obtida dividindo-se o peso de carcaça fria pelo seu comprimento da carcaça.

Seguindo as avaliações na meia-carcaça esquerda, realizou-se um corte horizontal entre a $12^{\mathrm{a}}$ e a $13^{\mathrm{a}}$ costelas, com o intuito de expor o músculo Longissimus dorsi para traçar o seu contorno em papel vegetal. A área da figura foi posteriormente determinada em mesa digitalizadora, por intermédio do software Site10. No mesmo local, foi medida a espessura de gordura subcutânea, obtida pela média aritmética de três observações.

Para a determinação da composição física da carcaça foi utilizada a técnica adaptada por Müller (1987). Na meia carcaça fria esquerda, foi retirada uma seção entre a 10 - 11 - $12^{\mathrm{a}}$ costelas, em que foi feita a separação física dos tecidos muscular, adiposo e ósseo, para posterior determinação da quantidade total e do porcentual destes, em relação à carcaça fria.

O delineamento experimental utilizado foi o inteiramente casualizado em arranjo fatorial 4 × 2 (frequências de fornecimento e categorias). Inicialmente os dados foram submetidos à análise de normalidade e variância pelo teste $F$, sendo as médias comparadas pelo teste de $t$ de Student, em nível de $5 \%$ de significância (SAS, 2001).

\section{RESULTADOSEDISCUSSÃO}

Não houve interação $(p>0,05)$ entre o número de fornecimento da dieta e a categoria animal para as características avaliadas. Em função disto, elas foram analisadas separadamente.

As frequências de fornecimento da dieta utilizada não promoveram diferença para as características quantitativas da carcaça ( $p>0,05)$ (tabela II), discordando de Gibson (1981) que encontrou melhor desempenho de bovinos alimentados várias vezes ao dia, sendo que esses apresentaram melhor acabamento de carcaça. As semelhanças nas características quantitativas da carcaça podem ser atribuídas ao peso de abate semelhante dos animais, já que estas características são altamente relacionadas ao peso de abate (Arboitte et al., 2004). Ferreira et al. (2009), alimentando os animais duas, três ou quatro vezes, não observaram diferença nas características da carcaça de vacas e novilhos confinados.

Os rendimentos de carcaça quente (RCQ) e fria (RCF) das fêmeas foram semelhantes, devido principalmente a semelhança entre os tratamentos do peso de abate e a utilização da mesma dieta para os diferentes tratamentos. No entanto, apresentou bons resultados com todos os tratamentos superando facilmente $50 \%$ de rendimento, com destaque para os animais do tratamento $1 \mathrm{~V} /$ C que apresentaram $56 \%$ de RCQ. Portanto, esse resultado atesta a não interferência das frequiências de fornecimento da dieta no rendimento de carcaça.

A espessura de gordura subcutânea (EGS) (tabela II) das carcaças foi semelhante $(\mathrm{p}=0,5017)$ entre as diferentes frequências do fornecimento da dieta, ficando dentro do intervalo de 3 a 6 mm de EGS buscada pelos frigoríficos. A deposição de gordura no animal está altamente relacionada ao peso de abate (Kuss et al., 2005), ao grupo genético (Menezes et al., 2005), à idade do animal e à densidade energética da dieta (Restle etal., 2001), características que foram 
Tabela II. Peso de abate, pesos de carcaças quentes (PCQ) e fria (PCF), rendimentos de carcaças quente $(R C Q)$ e fria $(R C F)$, perda ao resfriamento $(P R)$, espessura de gordura subcutânea (EGS) e EGS/100 kg de carcaça fria de animais recebendo diferentes frequiências do fornecimento do volumoso $(V)$ e concentrado $(C)$. (Slaughter weight, hot and cold carcass weights, hot and cold carcass yield, loss to cooling, subcutaneous fat thickness and subcutaneous fat thickness $/ 100 \mathrm{~kg}$ cold carcass of animals receiving different frequencies of the supply of roughage $(\mathrm{V})$ and supplement $(\mathrm{C})$ ).

\begin{tabular}{lcccccc}
\hline & \multicolumn{3}{c}{ Frequências do fornecimento da dieta } & Erro-padrão & p \\
& 2 V/C & 1 V/C & 1 V/2 C & 1 V/3 C & & \\
\hline Peso de abate, kg & 467,5 & 471,1 & 488,0 & 473,7 & 12,2 & 0,6620 \\
PCQ, kg & 260,5 & 263,6 & 267,0 & 263,4 & 7,90 & 0,9529 \\
PCF, kg & 252,2 & 254,3 & 257,7 & 254,3 & 7,72 & 0,9667 \\
RCQ, \% & 55,8 & 56,0 & 54,7 & 55,6 & 0,72 & 0,5937 \\
RCF, \% & 54,0 & 54,0 & 52,8 & 53,7 & 0,64 & 0,5075 \\
PR, \% & 3,31 & 3,75 & 3,61 & 3,61 & 0,61 & 0,9634 \\
EGS, mm & 5,6 & 5,5 & 4,5 & 5,1 & 0,56 & 0,5017 \\
EGS, \% & 2,25 & 2,14 & 1,74 & 2,05 & 0,23 & 0,4707 \\
\hline
\end{tabular}

semelhantes entre as frequências de fornecimento da dieta. Os animais alimentados com 2 V/C apresentaram média de 5,6 $\mathrm{mm}$, sendo a maior EGS. Por sua vez, os animais alimentados com $1 \mathrm{~V} / 2 \mathrm{C}$ apresentaram a menor EGS, com média de 4,5 mm, resultado que refletiu-se na EGS/100 kg de carcaça fria de $2,25 \%$ e $1,74 \%(p=0,4707)$ para os animais que receberam $2 \mathrm{~V} / \mathrm{C}$ e $1 \mathrm{~V} /$ $2 \mathrm{C}$, respectivamente.

Os comprimentos de carcaça, perna e braço, perímetro de braço e espessura de coxão, apresentaram semelhança entre as diferentes frequências de fornecimento da dieta (tabela III). Entretanto, os animais que receberam $1 \mathrm{~V} / 2 \mathrm{C}$ apresentaram resultados mais elevados para esses itens com 129; 72,$8 ; 41,6 ; 38,2$ e $27,1 \mathrm{~cm}$, respectivamente. Esses resultados foram obtidos devido ao maior peso de abate, porém não significativa $(\mathrm{p}=0,6620)$, deste tratamento $(1 \mathrm{~V} / 2 \mathrm{C})$, que foi de $488,0 \mathrm{~kg}$.

A conformação das carcaças não foi influenciada ( $\mathrm{p}=0,6258)$ pelas frequências do fornecimento do alimento. Os animais dos tratamentos apresentaram conformação classificada como regular típica com valores de 8,75; 8,37; 7,87 e 8,37 pontos (Müller,
1987) para os fornecimentos $2 \mathrm{~V} / \mathrm{C}, 1 \mathrm{~V} / \mathrm{C}, 1$ $\mathrm{V} / 2 \mathrm{Ce} 1 \mathrm{~V} / 3 \mathrm{C}$, respectivamente. Os animais recebendo $1 \mathrm{~V} / 2 \mathrm{C}$ obtiveram a menor conformação em relação aos outros tratamentos por apresentar o maior peso de abate e o menor rendimento de carcaça. No entanto, deve-se destacar a homogeneidade da conformação das carcaças para as diferentes freqüências de fornecimento de volumoso e concentrado, logo o produtor terá maior tranquilidade na hora de definir os horários de alimentação de seus animais confinados.

A área de olho de lombo (AOL) é influenciada por fatores como o tamanho do animal e nível alimentar. No presente estudo, não foi influenciada pelas diferentes freqüências de fornecimento da dieta utilizada ( $\mathrm{p}=0,3725)$, como também a área de lombo por $100 \mathrm{~kg}$ de carcaça fria (AOL/100) $(\mathrm{p}=0,2853)$, porém os animais do tratamento $1 \mathrm{~V} / 2 \mathrm{C}$ foram inferior aos outros com $26,5 \%$ de AOL/100, resultado que condiz com rendimento de carcaça obtido por esses animais que foi menor em relação aos demais.

O índice de compacidade da carcaça foi semelhante $(p=0,9913)$ entre as frequências de fornecimento da dieta e este resultado 
PAZDIORA ETAL.

Tabela III. Comprimentos, da carcaça, perna e braço, perímetro de braço e espessura de coxão, área de olho de lombo, índice de compacidade da carcaça (CC) e maturidade fisiológica de animais recebendo diferentes freqüências do fornecimento do volumoso $(V)$ e concentrado $(C)$. (Lengths, of carcass, leg and arm, upper arm and cushion thickness, ribeye area, carcass compactness index of and physiological maturity of animals receiving different frequencies of the supply of roughage $(\mathrm{V})$ and supplement $(\mathrm{C})$ ).

\begin{tabular}{|c|c|c|c|c|c|c|}
\hline & \multicolumn{4}{|c|}{ Frequências do fornecimento da dieta } & \multirow[t]{2}{*}{ Erro-padrão } & \multirow[t]{2}{*}{$\mathrm{p}$} \\
\hline & $2 \mathrm{~V} / \mathrm{C}$ & $1 \mathrm{~V} / \mathrm{C}$ & $1 \mathrm{~V} / 2 \mathrm{C}$ & $1 \mathrm{~V} / 3 \mathrm{C}$ & & \\
\hline \multicolumn{7}{|l|}{ Comprimentos } \\
\hline da carcaça, cm & 124,8 & 126,0 & 129,0 & 126,3 & 1,31 & 0,1747 \\
\hline de perna, $\mathrm{cm}$ & 70,8 & 70,6 & 72,8 & 71,6 & 0,95 & 0,3593 \\
\hline de braço, $\mathrm{cm}$ & 39,6 & 40,4 & 41,6 & 40,2 & 0,87 & 0,4471 \\
\hline Perímetro de braço, cm & 36,6 & 38,3 & 38,2 & 37,5 & 0,83 & 0,4326 \\
\hline Espessura do coxão, cm & 26,8 & 26,0 & 27,1 & 26,7 & 0,49 & 0,4235 \\
\hline Conformação ${ }^{1}$ & 8,75 & 8,37 & 7,87 & 8,37 & 0,46 & 0,6258 \\
\hline Área de olho de lombo, $\mathrm{cm}^{2}$ & 71,0 & 72,7 & 68,2 & 68,2 & 2,10 & 0,3725 \\
\hline Área de olho de lombo/100, \% & 28,0 & 28,8 & 26,5 & 30,0 & 0,88 & 0,2853 \\
\hline Índice da CC, kg/cm & 2,00 & 2,00 & 1,99 & 2,00 & 0,05 & 0,9913 \\
\hline Maturidade fisiológica² & 9,50 & 9,50 & 9,12 & 10,62 & 0,67 & 0,4384 \\
\hline
\end{tabular}

'Escala de pontuação: 1 a 3= inferior; 4 a 6= má; 7 a 9= regular; 10 a 12= boa; 13 a 15= muito boa e 16 a 18 superior (Müller, 1987). ${ }^{2}$ Escala de pontuação conforme a ossificação das cartilagens variando 1 a 15 pontos, sendo menor valor mais ossificado (Müller, 1987).

deve-se aos animais apresentarem semelhanças no comprimento e no peso de carcaça. A maturidade fisiológica calculada pelo grau de ossificação das cartilagens, variou de 9,12 a 10,62 pontos, não sendo influenciada $(\mathrm{p}=0,4384)$ pelas frequências do fornecimento da dieta, devido a semelhança de idade dos animais utilizados em cada tratamento.

Analisando os pesos absolutos e relativos dos cortes comerciais (tabela IV), constatou-se que os cortes dianteiro, costilhar e traseiro, não apresentaram diferença significativa de acordo com freqüências de alimentação. Dentre esses cortes, o traseiro contém a maioria dos músculos de maior taxa de crescimento, localizados nos membros posteriores (Biceps femoris, Gluteus medius, Semitendinosus, Semimembranosus e Addutor) e próximos à coluna vertebral (Psoas major e Longissimus), mas a quantidade de gordura na carcaça pode alterar a participação desses cortes comerciais (Berg e Butterfield, 1976). No corte dianteiro, onde se encontram os músculos de menor valor, principalmente em função da maciez da carne, a maior parte dos músculos é direcionada para a confecção de carne moída.

No presente estudo, a igualdade entre os cortes comerciais se deve aos animais apresentaram semelhança no peso de abate. Restle et al. (2002) verificaram coeficiente de correlação altamente positivo do peso de abate com os pesos de traseiro, dianteiro e costilhar, quando avaliaram as características quantitativas da carcaça de vacas de descarte de diferentes grupos genéticos. Neste sentido, Jardim et al. (1988) verificaram que $58 \%$ da variação total no peso do dianteiro, $50 \%$ da variação total no peso do costilhar e $92 \%$ da variação total no peso do traseiro se devem à variação no peso da carcaça.

A participação dos tecidos na carcaça, bem como a relação entre os mesmos, 
Tabela IV. Pesos e porcentagem do traseiro, dianteiro e costilhar de animais recebendo diferentes freqüências do fornecimento do volumoso $(V)$ e concentrado $(C)$. (Weights and percentage of the back, front and sidecut of animals receiving different frequencies of the supply of roughage (V) and supplement $(\mathrm{C})$ ).

\begin{tabular}{lcccccc}
\hline & \multicolumn{3}{c}{ Frequências do fornecimento da dieta } & \multirow{2}{*}{ Erro-padrão } & p \\
& 2 V/C & 1 V/C & 1 V/2 C & 1 V/3 C & & \\
\hline Traseiro, kg & 63,3 & 64,6 & 66,4 & 64,2 & 2,0 & 0,8690 \\
Dianteiro, kg & 45,9 & 46,8 & 47,0 & 46,9 & 1,57 & 0,9575 \\
Costilhar, kg & 16,5 & 16,3 & 17,1 & 16,6 & 0,48 & 0,6636 \\
Traseiro, \% & 25,12 & 25,47 & 25,86 & 25,24 & 0,25 & 0,7389 \\
Dianteiro, \% & 18,22 & 18,36 & 18,25 & 18,43 & 0,14 & 0,5276 \\
Costilhar, \% & 6,52 & 6,40 & 6,66 & 6,51 & 0,14 & 0,7631 \\
\hline
\end{tabular}

avaliada através das relações músculo:gordura, músculo:osso e músculo + gordura/osso, foi semelhante para os diferentes números de fornecimento da alimentação (tabela V). Segundo Berg e Buterfield (1976), entre os tecidos que compõem a carcaça, o muscular é o mais importante, uma vez que é o mais procurado pelo consumidor. Portanto, a carcaça deve apresentar quantidade máxima de músculo, mínima de osso e gordura de acordo com a preferência do consumidor. Vaz e Restle (1998) comentam que essas características têm fundamental importância quando se pretende aumentar a aceitação da carne bovina, já que a mesma perdeu bastante espaço na mesa dos con- sumidores para carnes de outros tipos de animais ou mesmo para a proteína vegetal.

$\mathrm{O}$ aumento nas frequências do fornecimento da dieta, quando se espera uma diferença nas características da carcaça, mostrou-se uma prática não recomendada para terminação de bovinos confinados, pois aumenta o dispêndio de mão-de-obra no manejo, não havendo diferença estatística significativa nas características estudadas.

$\mathrm{O}$ peso de abate foi significativamente maior $(\mathrm{p}<0,0001)$ para as vacas $(525,5 \mathrm{~kg}) \mathrm{em}$ relação às novilhas $(424,7 \mathrm{~kg})$ (tabela VI). Esse resultado pode ser explicado pelo fato das novilhas ainda estarem em fase de crescimento corporal. Isso pode ser confir-

Tabela $\boldsymbol{V}$. Composição da carcaça de acordo com a freqüência do volumoso $(V)$ e concentrado $(C)$. (Carcass composition in accordance with the frequency of roughage $(\mathrm{V})$ and supplement $(\mathrm{C}))$.

\begin{tabular}{lcccccc}
\hline & \multicolumn{3}{c}{ Frequências do fornecimento da dieta } & Erro-padrão & $p$ \\
& 2 V/C & 1 V/C & 1 V/2 C & 1 V/3 C & & \\
\hline Músculo, kg & 140,9 & 148,0 & 150,0 & 143,5 & 8,33 & 0,8620 \\
Gordura, kg & 72,0 & 71,8 & 73,1 & 71,1 & 4,8 & 0,9935 \\
Osso, kg & 39,2 & 36,0 & 37,7 & 39,5 & 2,4 & 0,7277 \\
Músculo, \% & 56,1 & 58,0 & 57,3 & 56,4 & 2,6 & 0,9614 \\
Gordura, \% & 28,3 & 28,2 & 28,2 & 28,2 & 1,83 & 0,9994 \\
Osso, \% & 15,4 & 14,2 & 14,6 & 15,5 & 0,74 & 0,5547 \\
Relação músculo:gordura & 2,1 & 2,2 & 2,1 & 2,0 & 0,21 & 0,9735 \\
Relação músculo:osso & 3,7 & 4,2 & 4,0 & 3,8 & 0,32 & 0,7123 \\
Relação músculo+gordura:osso & 5,5 & 6,2 & 6,0 & 5,6 & 0,35 & 0,5038 \\
\hline
\end{tabular}


PAZDIORA ETAL.

Tabela VI. Caracteristicas das carcaças de acordo com a categoria animal. (Carcass characteristics according to the animal category).

\begin{tabular}{lcccr}
\hline & Vaca & Novilha & Erro-padrão & $\mathrm{p}$ \\
\hline Peso de abate, $\mathrm{kg}$ & 525,5 & 424,7 & 8,6 & $<0,0001$ \\
Espessura de gordura, mm & 5,65 & 4,71 & 0,39 & 0,1082 \\
Espessura de gordura/100 kg de carcaça fria, \% & 2,01 & 2,08 & 0,16 & 0,7729 \\
Peso de carcaça quente, kg & 291,0 & 236,1 & 5,59 & $<0,0001$ \\
Peso de carcaça fria, kg & 281,7 & 227,5 & 5,46 & $<0,0001$ \\
Rendimento de carcaça quente, \% & 55,4 & 55,6 & 0,51 & 0,7344 \\
Rendimento de carcaça fria, \% & 53,6 & 53,6 & 0,45 & 0,9769 \\
Perda ao resfriamento, \% & 3,31 & 3,92 & 0,43 & 0,4120 \\
\hline
\end{tabular}

mado pelo menor comprimento de carcaça apresentado por essa categoria em relação às vacas. Restle et al. (2001), ao verificarem que novilhas Charolês abatidas aos três anos de idade apresentaram menor peso de abate do que vacas de descarte da mesma raça, concluíram que as novilhas não haviam completado o seu crescimento, o que foi confirmado pelo menor comprimento de carcaça desses animais. O mesmo foi constatado por Restle et al. (2000) que trabalhando com vacas de descarte de diferentes idades terminadas em pastagem cultivada de inverno verificaram que o peso de abate aumentou com o avanço da idade das fêmeas, sendo $416 \mathrm{~kg}$ para as de quatro anos de idade e $453 \mathrm{~kg}$ para as vacas com sete a oito anos.

A EGS, em mm e mm/100 kg PCF, não diferiu $(\mathrm{p}=0,1082)$ entre as fêmeas. Segundo Di Marco (1994), a quantidade de gordura depositada é condicionada por vários fatores, como raça, sexo, condição sexual, peso vivo, histórico alimentar e velocidade de ganho de peso. O mesmo autor ainda revela que o depósito de gordura inicia-se pela gordura intermuscular; seguindo nos órgãos internos e nas vísceras, após, inicia o acúmulo de gordura subcutânea e, por último, a gordura intramuscular. Analisando o efeito da idade e da categoria de bovinos da raça Charolês, Pacheco et al. (2013) observaram valores de 3,8 e 3,6 mm de gordura sobre a carcaça de novilhos e novilhas abatidos aos 23 meses de idade, e 4,0 $\mathrm{mm}$ em carcaças de vacas de descarte abatidas com 90 meses.

$\mathrm{O}$ peso de carcaça quente e fria foram maiores ( $\mathrm{p}<0,0001)$ para as vacas $(291 \mathrm{e} 281$ kg) em relação às novilhas (236,1 e 229,5 kg). Possivelmente, esta diferença está relacionada com o maior peso de abate das vacas, que reflete em carcaças mais pesadas. Entretanto, o RCQ e RCF não diferiram ( $p>0,05)$ entre as categorias. Restle et al. (2000) ao avaliarem o rendimento de carcaça de novilhas e vacas Charolês, verificaram maior RCF para as novilhas $(51,09 \%)$ em relação às vacas $(48,91 \%)$. Vaz et al. (2002) constataram que não houve diferença significativa para o PCF entre vacas e novilhos, em função do maior rendimento de carcaça dos novilhos $(49,14 \%)$ em relação as vacas $(46,62 \%)$, mesmo as vacas tendo apresentado maior peso de abate em comparação aos novilhos (475,7vs. 426,7 kg).

Ao observar a tabela VII, verifica-se que o comprimento de carcaça foi significativamente maior $(p<0,05)$ para as vacas $(132 \mathrm{~cm})$ em relação às novilhas $(121,1 \mathrm{~cm})$. O comprimento de carcaça geralmente possui alta correlação com o peso de carcaça, e isto pode ser observado na tabela VI, que confirma maiores pesos de carcaça para as vacas. Os valores de comprimento de perna e de braço, bem como perímetro de braço foram superiores $(p<0,05)$ para as vacas, cujos respectivos valores foram 72,$8 ; 41,7 \mathrm{e}$ 


\section{FREQUÊNCIAS DA ALIMENTAÇÃO E CARACTERÍSTICAS DA CARCAÇA BOVINA}

$38,8 \mathrm{~cm}$ vs. 70,$2 ; 39,3$ e $36,5 \mathrm{~cm}$ apresentados pelas novilhas, respectivamente.

A AOL foi maior $(\mathrm{p}<0,01)$ para as vacas $\left(75 \mathrm{~cm}^{2}\right)$ do que para as novilhas $\left(65 \mathrm{~cm}^{2}\right)$. Provavelmente, a maior AOL apresentada pelas fêmeas mais velhas se deve ao seu pleno desenvolvimento corporal, neste caso, o depósito muscular já foi praticamente concluído e deu lugar ao depósito de tecido adiposo, ao contrário das novilhas que ainda estão em fase de crescimento corporal e acúmulo de tecido muscular. Isto pode ser comprovado, quando comparada a AOL em porcentagem da carcaça em que esta diferença deixou de existir.

A conformação da carcaça que é a avaliação subjetiva da expressão muscular e está correlacionada positivamente com a porção comestível da carcaça, não diferiu significativamente entre as categorias estudadas. No entanto, a espessura do coxão foi maior $(\mathrm{p}=0,0003)$ para as vacas $(27,7 \mathrm{~cm})$ em comparação as novilhas $(25,6 \mathrm{~cm})$. As novilhas apresentaram carcaças com melhor $(\mathrm{p}<0,01)$ grau de maturidade fisiológica $(12,6$ pontos) do que as vacas (6,8 pontos). Este resultado era esperado, uma vez que o grau de ossificação dos processos espinhosos das vértebras lombares e sacrais aumenta com o avanço da idade dos animais (Müller, 1987). O índice de compacidade foi maior $(\mathrm{p}=0,0002)$ para as vacas cujo valor apresentado foi de $2,1 \mathrm{~kg} / \mathrm{cm} v s .1,9 \mathrm{~kg} / \mathrm{cm}$ apresentados pelas novilhas. Possivelmente, o índice de compacidade foi influenciado pelo maior peso de carcaça das vacas, que, por sua vez, pode ter influencia do maior peso e tamanho dos ossos dos animais adultos, já que a conformação foi semelhante entre as categorias avaliadas.

Quanto aos cortes comerciais e a composição física da carcaça, as vacas apresentaram maior peso absoluto de traseiro, dianteiro e costilhar, assim como músculo, gordura e osso em relação às novilhas (tabela VIII). Estes resultados são consequência do maior peso de carcaça fria para as vacas. Já quando analisados em relação à porcentagem, apenas o traseiro foi superior para as novilhas. Estes dados

Tabela VII. Comprimentos, da carcaça, perna e braço, perímetro de braço e espessura de coxão, área de olho de lombo, índice de compacidade da carcaça e maturidade fisiológica de acordo com a categoria animal. (Lengths, of carcass, leg and arm, upper arm and cushion thickness, ribeye area, carcass compactness index of and physiological maturity according to animal category).

\begin{tabular}{|c|c|c|c|c|}
\hline & Vaca & Novilha & Erro-padrão & $\mathrm{p}$ \\
\hline Comprimento da carcaça, $\mathrm{cm}$ & 132,0 & 121,1 & 0,92 & $<0,0001$ \\
\hline Comprimento de perna, $\mathrm{cm}$ & 72,8 & 70,2 & 0,67 & 0,0113 \\
\hline Comprimento de braço, $\mathrm{cm}$ & 41,7 & 39,3 & 0,61 & 0,0129 \\
\hline Perímetro de braço, $\mathrm{cm}$ & 38,8 & 36,5 & 0,59 & 0,0092 \\
\hline Espessura do coxão, cm & 27,7 & 25,6 & 0,31 & 0,0003 \\
\hline Conformação, pontos ${ }^{1}$ & 8,31 & 8,37 & 0,32 & 0,8945 \\
\hline Área de olho de lombo, $\mathrm{cm}^{2}$ & 75,0 & 65,0 & 1,48 & $<0,0001$ \\
\hline Área de olho de lombo/100 kg de carcaça fria, \% & 26,8 & 28,4 & 4,89 & 0,0831 \\
\hline Índice de compacidade da carcaça, kg/cm & 2,1 & 1,9 & 0,04 & 0,0002 \\
\hline Maturidade fisiológica, pontos ${ }^{2}$ & 6,8 & 12,6 & 0,47 & $<0,0001$ \\
\hline
\end{tabular}

${ }^{1}$ Escala de pontuação: 1 a $3=$ inferior; 4 a $6=$ má; 7 a $9=$ regular; 10 a 12= boa; 13 a $15=$ muito boa e 16 a 18 superior (Müller, 1987). ${ }^{2}$ Escala de pontuação conforme a ossificação das cartilagens variando 1 a 15 pontos, sendo menor valor mais ossificado (Müller, 1987). 
PAZDIORA ETAL.

Tabela VIII. Cortes comerciais e composição da carcaça de acordo com a categoria animal. (Commercial cuts and carcass composition according to the animal category).

\begin{tabular}{lcccc}
\hline & Vaca & Novilha & Erro-padrão & $\mathrm{p}$ \\
\hline Traseiro, kg & 70,4 & 58,8 & 1,41 & $<0,0001$ \\
Dianteiro, kg & 51,48 & 41,8 & 1,11 & $<0,0001$ \\
Costilhar, kg & 18,66 & 14,57 & 0,33 & $<0,0001$ \\
Traseiro, \% & 24,9 & 25,8 & 0,18 & 0,0017 \\
Dianteiro, \% & 18,3 & 18,4 & 0,10 & 0,5178 \\
Costilhar, \% & 6,63 & 6,42 & 0,10 & 0,1578 \\
Músculo, kg & 159,59 & 131,60 & 5,89 & 0,0026 \\
Gordura, kg & 80,82 & 63,17 & 3,39 & 0,0012 \\
Osso, kg & 41,48 & 34,78 & 1,69 & 0,0100 \\
Músculo, \% & 56,62 & 57,27 & 1,85 & 0,8034 \\
Gordura, \% & 28,78 & 27,57 & 1,30 & 0,5107 \\
Osso, \% & 14,68 & 15,15 & 0,52 & 0,5359 \\
Relação músculo:gordura & 2,04 & 2,16 & 0,15 & 0,5793 \\
Relação músculo:osso & 3,96 & 3,89 & 0,23 & 0,8420 \\
Relação músculo + gordura:osso & 5,94 & 5,71 & 0,23 & 0,5079 \\
\hline
\end{tabular}

corroboram com os encontrados por Restle et al. (2001) que verificaram maior porcentagem de traseiro nas novilhas em relação às vacas. Essa superioridade dos animais jovens na participação do traseiro na carcaça é desejável, uma vez que a maioria dos cortes nobres presentes na carcaça se encontra nesta porção.

\section{BIBLIOGRAFIA}

ANUALPEC. 2010. Anuário da pecuária brasileira. Agra FNP pesquisas Ltda. São Paulo. 380 pp. Arboitte, M.Z.; Restle, J.; Alves Filho, D.C.; Pascoal, L.L.; Pacheco, P.S. e Soccal, D.C. 2004. Características da carcaça de novilhos $5 / 8$ Nelore - $3 /$ 8 Charolês abatidos em diferentes estádios de desenvolvimento. Rev Bras Zootecn, 33: 969977.

Berg, R.T. and Butterfield, R.M. 1976. New concepts of cattle growth. Sidney University. New York. $240 \mathrm{pp}$.

Chase, L.J.; Wangsness, P.J. and Baumgardt, B.R. 1976. Feeding behaviour of stress fed a complete mixed ration. J Dairy Sci, 59: 1923-1928.

Di Marco, O.N. 1994. Crecimiento y respuesta animal. Associación Argentina de Producción Animal. Buenos Aires. 129 pp.

\section{CONCLUSÕES}

As frequências de fornecimento do volumoso e concentrado, em confinamento, não interferem nas características da carcaça. A categoria animal utilizada influencia nas características qualitativas e quantitativas da carcaça de bovinos de corte.

Ferreira, J.J.; Menezes, L.F.G. de; Restle, J.; Brondani, I.L.; Alves Filho, D.C. e Callegaro, A.M. 2009. Características de carcaça de vacas de descarte e novilhos mestiços Charolês $\times$ Nelore em confinamento sob diferentes frequências de alimentação. Rev Bras Zootecn, 38: 1974-1982.

Gibson, J.O. 1981. The effects of feeding frequency on growth and efficiency of food utilization of ruminants. Anim Prod, 32: 275-283.

Jardim, P.O.C.; Guarenti, N.M. e Osório, J.C.S. 1988. Avaliação dos cortes dianteiro, costilhar e serrote em vacas de descarte. Pesqui Agropecu Bras, 23: 543-549.

Kuss, F.; Restle, J.; Brondani, I.L.; Alves Filho, D.C.; Perottoni, J.; Missio, R.L. e Amaral, G.A. 2005. Composição física da carcaça e qualidade

Archivos de zootecnia vol. 62, núm. 240, p. 576. 


\section{FREQUÊNCIAS DA ALIMENTAÇÃO E CARACTERÍSTICAS DA CARCAÇA BOVINA}

da carne de vacas de descarte de diferentes grupos genéticos terminadas em confinamento com distintos pesos. Rev Bras Zootecn, 34: $1285-1296$.

Menezes, L.F.G.; Restle, J., Vaz, F.N.; Brondani, I.L.; Alves Filho, D.C.; Freitas, A.K. e Metz, P.A.M. 2005. Composição física da carcaça e qualidade da carne de novilhos de gerações avançadas do cruzamento alternado entre as raças Charolês e Nelore, terminados em confinamento. Rev Bras Zootecn, 34: 946-956.

Müller, L. 1987. Normas para avaliação de carcaças e concurso de carcaça de novilhos. 2. $\stackrel{\text { ed. }}{\text { ed }}$ Universidade Federal de Santa Maria. Santa Maria. $31 \mathrm{pp}$.

NRC. 1996. National Research Council. Nutrient requeriment of beef cattle. 7. ${ }^{\mathrm{a}}$ ed. National Academy Press. Washington. 242 pp.

Pacheco, P.S.; Restle, J.; Missio, R.L.; Menezes, L.F.G.; Rosa, J.R.P.; Kuss, F.; Alves Filho, D.C.; Neiva, J.N.M. e Donicht, P.A.M.M. 2013. Características da carcaça e do corpo vazio de bovinos Charolês de diferentes categorias abatidos com similar grau de acabamento. Arq Bras Med Vet Zoot, 65: 281-288.

Restle, J.; Vaz, F.N. e Pascoal, L.L. 2000. Características de carcaça de vacas de diferentes idades, terminadas em pastagem cultivada de estação fria sob pastejo horário mais suplementação. Reunião Anual da Sociedade Brasileira de Zootecnia, 37. Anais... Sociedade Brasileira de Zootecnia. Viçosa, MG.

Restle, J.; Cerdótes, L. e Vaz, F.N. 2001. Características da carcaça e da carne de novilhas e vacas de descarte Charolês, terminadas em confinamento. Rev Bras Zootecn, 30: 10651073.

Restle, J.; Pascoal, L.L.; Faturi, C.; Alves Filho, D.C.; Brondani, I.L.; Pacheco, P.S. e Peixoto, L.A.O. 2002. Efeito do grupo genético e da heterose nas características quantitativas da carcaça de vacas de descarte terminadas em confinamento. Rev Bras Zootecn, 31: 350-362.

SAS. 2001. SAS Language Reference. Version 6. SAS Institute Inc. Cary, NC. 1042 pp.

Vaz, F.N. e Restle, J. 1998. Produção de carne com qualidade. In: Restle, J.; Brondani, I.L.; Pascoal, L.L. (Eds.). Produção intensiva com qualidade em bovinos de corte. Universidade Federal de Santa Maria. Santa Maria. pp. 104-119.

Vaz, F.N.; Restle, J.; Quadros, A.R.; Pascoal, L.L.; Sanchez, L.M.B.; Rosa, J.R.P. e Memezes, L.F.G. 2002. Características da carcaça e da carne de novilhos e de vacas de descarte Hereford, terminados em confinamento. Rev Bras Zootecn, 31: 1501-1510. 